\section{'Jintao', a Novel, Hairless, Yellow-fleshed Kiwifruit}

\author{
Hongwen Huang ${ }^{1}$, Shengmei Wang, Renhuang Huang, \\ Zhengwang Jiang, and Zhonghui Zhang \\ Wuhan Institute of Botany and Wuhan Botanical Garden, The Chinese \\ Academy of Sciences, Wuhan, Hubei 430074, P.R. China
}

Additional index words. kiwifruit, cultivar improvement, yellow flesh, Actinidia chinensis

'Jintao' is a new yellow-fleshed kiwifruit (Actinidia chinensis Planch) developed from the breeding program at the Wuhan Institute of Botany (WIB), in Wuhan, Hubei, People's Republic of China. 'Jintao' is a midseason cultivar that ripens three to four weeks before the standard commercial cultivar [A. deliciosa (A. Chev.) C.F. Liang et A.R. Ferguson] 'Hayward'. It is sweeter than 'Hayward' and has a smooth skin. 'Jintao' was selected from A. chinensis and offers growers in warmer climates an alternative to 'Hayward', because of its higher productivity, better fruit quality, and improved heat tolerance. 'Jintao', which means golden peach in Chinese, is named in recognition of its yellow flesh and the common Chinese name, Mihou-tao, or monkey peach.

Actinidia deliciosa and A. chinensis, the kiwifruit of international commerce, are large sized fruit and good flavored. These two Actinidia species are native only in China. Actinidia Lindl. is comprised of 66 species and 118 taxa, most of which are native to China (Huang et al., 2000). The economic potential of $A$. deliciosa was exploited in New Zealand following the introduction of a Chinese seedlot in 1904, and the first commercial orchard was established in New Zealand $\approx 1930$ (Ferguson and Bollard, 1990). Since the early 1970's, an international kiwifruit industry of more than 100,000 hectares with an annual production one million tons has been developed (Huang and Ferguson, 2001). 'Hayward', the first cultivar selected in New Zealand in the early $20^{\text {th }}$ century (Ferguson and Bollard, 1990), is essentially the only commercial cultivar grown in New Zealand, Italy, Chile, France, Greece, Japan, and the United States, and has become the standard cultivar of international commerce. Other A. deliciosa cultivars, such as 'Top Star' ${ }^{\circledR}$ in Italy or 'Tomua' in New Zealand, have been planted on a small scale. A rapid expansion of the industry has brought about an increased interest in developing new cultivars for today's more competitive world market.

In 1978, a national germplasm repository and breeding program for Actinidia was established at the Wuhan Institute of Botany (WIB) (Huang et al., 1996). The goals of the program were to develop an ex situ repository of currently known Actinidia species and to develop superior cultivars through breeding and selection. A major objective of the WIB breeding program is to develop nonpubescent, sweet,

Received for publication 27 Aug. 2001. Accepted for publication $16 \mathrm{Feb}$. 2002. This research was partially supported by NSF of China (30070082), the European Union (INCO-DC IC18CT970183) and the Chinese Academy of Sciences.

${ }^{1}$ To whom reprint requests should be sent. Professor of Plant Genetics and Breeding, Wuhan Institute of Botany, The Chinese Academy of Sciences, Wuhan, Hubei 430074, P.R. China. E-mail address: hongwen@public.wh.hb.cn yellow-fleshed cultivars with good storage life equivalent to 'Hayward' or better. The cultivar described here is one of the selections of this kind.

\section{Origin}

'Jintao' was selected from wild vines during the national Actinidia germplasm survey, 1980 to 1982 . The original vine was found in 1981 in Wuning county, Jiangxi province, southeast China. The vine was identified as Wuzhi 81-1 and evaluated for fruit quality, characteristics of flowering, fruiting and yielding, and growth requirements in the natural environment at the site in three successive years. Cuttings were collected and propagated by grafting. 'Jintao was initially field-tested as Wuzhi No. 6 at the WIB breeding orchard. It has been evaluated extensively in many experimental stations and commercial orchards of 12 provinces in central, northeast, southeast
Fig. 1. Fruit of 'Jintao' kiwifruit.
China, and has been tested as WIB-C-6 in three experiment trials in Italy, Greece, and France (Ferguson, 2001). 'Jintao' has been officially released in Italy by a propagation right sale in 2001.

\section{Description}

Vines are moderately vigorous. Bud burst occurs in early of March at WIB (lat. 30 $37^{\circ} \mathrm{N}$, long. $114^{\circ} 8^{\prime} \mathrm{E}$; having a typical continental climate with cold winters averaging between 7.7 and $-1.1^{\circ} \mathrm{C}$ in January and hot summers averaging between 33.8 and $25.6^{\circ} \mathrm{C}$ in July). Leaves are medium sized and oblate in shape (13 to $14 \mathrm{~cm}$ long and 14 to $17 \mathrm{~cm}$ broad), with emarginated blade tip and open blade base. The upper surface of the leaves is dark green and glossy, but the lower surface is densely tomentose. Leaf petiole is red colored, 7 to 10 $\mathrm{cm}$ long. At WIB full bloom is in late of April, as compared to the flowering of Hayward in early May. By averaging data of different locations, flowering time of 'Jintao' is $8 \mathrm{~d}$ earlier than that of 'Hayward'. Flowers are 4.5 $\mathrm{cm}$ in diameter and have 30 to 35 styles. Most flowers are single and are produced from the first to seventh basal nodes of the current fruiting shoots. Short and medium new shoots are major bearers, with an average of eight fruits per shoot and fruit set as high as $95 \%$. At WIB, fruit harvest (soluble solids $\geq 7 \%$ ) is from middle to late September, as compared to the fruit harvest of 'Hayward' from middle to late October. On average at different locations, fruit harvest of 'Jintao' is 20 to $25 \mathrm{~d}$ earlier than that of Hayward. Fruit are long, cylindrical, and uniform, with average length ranging from 6.3 to $7.5 \mathrm{~cm}$ and 3.7 to $4.2 \mathrm{~cm}$ in diameter (Fig. 1). The fruit weight ranges from 65 to $120 \mathrm{~g}$ with an average of $85 \mathrm{~g}$. The skin is almost hairless and light brown colored. The flesh is green yellow when fruit is harvested and tends to become yellow and orangeyellow during postharvest maturity (Table 1). The fruit has a tender texture, is juicy and

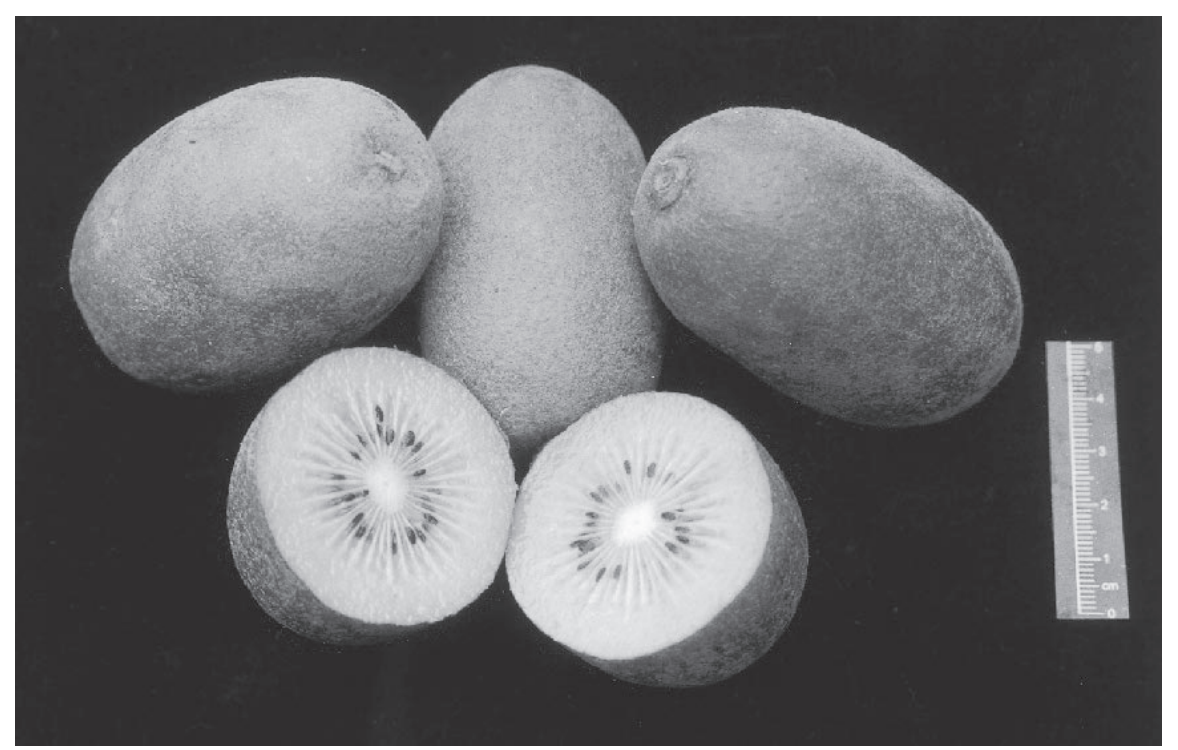


sweet having a desirable balanced sugar-acid averages $18 \%$ soluble solids, $7.8 \%$ total sugar, $2.1 \%$ acids and $150 \mathrm{mg}$ vitamin $\mathrm{C} / 100 \mathrm{~g}$ fresh fruit (Table 1). The fruit are considered less seedy, with $\approx 350$ seeds per fruit.

\section{Performance}

'Jintao' is productive, with a regular yielding habit. Under normal orchard management, it produces total yields double $(45000 \mathrm{~kg}$ to $58000 \mathrm{~kg} \cdot \mathrm{ha}^{-1}$ ) that of 'Hayward'. The cultivar is precocious, typically fruiting in the second season after grafting and reaching full produccontent that is pleasant to the palate. The fruit

tion in five years. The storability is the primary improvement of 'Jintao' over the other A. chinensis cultivars. The relatively thick peel (average $50 \mu \mathrm{m}$ vs. $\approx 70 \mu \mathrm{m}$ of Hayward) and high acid content increases its storage and shelf life equivalent to standard cultivar Hayward, and also reduces vitamin C loss in storage (Table 1). In a 1992 storage test, the fruit were harvested on 18 Sept. with field temperature of $31^{\circ} \mathrm{C}$, resulting in $100 \%$ and $94 \%$ marketable fruits, after one month of ambient storage (temperature ranging from 22 to $13^{\circ} \mathrm{C}$ ) and four-month cool storage $\left(4^{\circ} \mathrm{C}\right)$, respectively. 'Jintao' is considered heat tolerant in southeastern China, but it performs better in

Table 1. Fruit quality characteristics of 'Jintao' compared with standard cultivar 'Hayward'.

\begin{tabular}{|c|c|c|}
\hline Characteristic & Jintao & Hayward \\
\hline Harvest period & 15-25 Sept. & 15-20 Oct. \\
\hline Fruit wt $(\mathrm{g})$ & $85 \pm 10$ & $90 \pm 06$ \\
\hline Skin color & brown & brown \\
\hline Flesh color ${ }^{y}$ & yellow & green \\
\hline & $(\mathrm{L}=61.9 ; \mathrm{a}=-3.8 ; \mathrm{b}=27.6)$ & $(\mathrm{L}=62.0 ; \mathrm{a}=-12.0 ; \mathrm{b}=30.6)$ \\
\hline Flesh firmness at harvest ${ }^{\mathrm{x}}\left(\mathrm{kg} / \mathrm{cm}^{2}\right)$ & $6.8 \pm 0.8$ & $7.2 \pm 0.7$ \\
\hline Firmness after storage ${ }^{\mathrm{w}}\left(\mathrm{kg} / \mathrm{cm}^{2}\right)$ & $2.8 \pm 1.2$ & $4.5 \pm 1.5$ \\
\hline Soluble solids at harvest ${ }^{\mathrm{x}}(\%)$ & $12 \pm 1.8$ & $6.5 \pm 0.5$ \\
\hline Soluble solids after storage ${ }^{\mathrm{w}}(\%)$ & $18 \pm 4$ & $12 \pm 2$ \\
\hline Acids at harvest ${ }^{x}(\%)$ & 2.3 & 3.1 \\
\hline Acids after storage ${ }^{\mathrm{w}}(\%)$ & 2.1 & 2.1 \\
\hline Vitamin $C$ at harvest ${ }^{\mathrm{x}}(\mathrm{mg} / 100 \mathrm{~g})$ & $152 \pm 20$ & $86 \pm 18$ \\
\hline Vitamin $\mathrm{C}$ after storage $^{\mathrm{w}}(\mathrm{mg} / 100 \mathrm{~g})$ & $137 \pm 15$ & $53 \pm 14$ \\
\hline Sweetness $^{\mathrm{v}}$ & $4.2 \pm 0.8$ & $3.4 \pm 0.6$ \\
\hline Sourness ${ }^{v}$ & $3.1 \pm 0.7$ & $3.8 \pm 0.8$ \\
\hline Acceptability $^{\mathrm{v}}$ & $3.9 \pm 0.7$ & $3.5 \pm 0.6$ \\
\hline
\end{tabular}

${ }^{2}$ Twenty to 25 randomly selected fruits at the WIB breeding orchard were measured.

${ }^{y}$ Measured by LI-COR Chromameter CR 300, L = lightness, $\mathrm{a}=$ value of red and green colors, $\mathrm{b}=$ value of yellow and blue colors.

${ }^{x}$ Average value of the data collected during 1994-99.

${ }^{\text {w}}$ Average value of the data collected during 1998-2000.

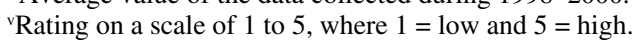

areas of 800 to $1000 \mathrm{~m}$ elevation where the cultivar has increased fruit skin thickness, soluble solids contents, sugar, vitamin $\mathrm{C}$, and better storage life and flavor. We observed in a regional variety trial that the high elevation could resulted in increase of fruit skin thickness up to $72 \mu \mathrm{m}$, soluble solids up to $21.5 \%$, vitamin C up to $197 \mathrm{mg} / 100 \mathrm{~g}$.

The selected pollinizer for 'Jintao' is Moshan No 4. Heavy winter dormant pruning is recommended.

\section{Availability}

'Jintao' has been licensed for propagation to the Consorzio Kiwi Gold for member countries of the European Union. 'Jintao' plants can been purchased from the Consorzio Kiwi Gold, Pievesestina di Cesena, via della Cooperazione 80, Italy. Wuhan Institute of Botany, Moshan, Wuhan city, Hubei 430074, P.R. China, has the plant variety rights to 'Jintao'.

\section{Literature Cited}

Ferguson, A.R. and E.G. Bollard. 1990. Domestication of the kiwifruit, p. 165-246. In: I.J. Warrington and G.C Weston (eds.). Kiwifruit: Science and management. Ray Richards Publishing, Auckland, N.Z.

Ferguson, A.R. 2001. Kiwifruit: Is China a threat? The Orchardist of New Zealand 74:40-44.

Huang, H., F. Dane, Z. Wang, Z. Jiang, R. Huang, and S. Wang. 1996. Isozyme inheritance and variation in Actinidia. Heredity 77:328-336.

Huang, H., J. Gong, S. Wang, Z. He, Z. Zhang, and J. Li. 2000. Genetic diversity in the genus Actinidia. Chinese Biodiversity 8:1-12 (in Chinese).

Huang, H., and A.R. Ferguson. 2001. Kiwifruit in China. N.Z. J. Crop Hort Sci 29:1-14. 